\title{
Bethesda Unit
}

National Cancer Institute

\section{Source}

National Cancer Institute. Bethesda Unit. NCI Thesaurus. Code C117966.

A unit of measurement for blood coagulation inhibitor activity, expressed in the amount

of an inhibitor neutralizing 50\% of a coagulant during the incubation period per unit of volume equal to one milliliter. 